\title{
Biologic drugs set to top 2012 sales
}

Move aside, small-molecule drugs for common diseases. Three biologic medicines initially developed to treat rheumatoid arthritis-a joint disorder that afflicts just $1 \%$ of the population worldwide - are on track to top the sales charts this year. According to forecasts compiled by Thomson Reuters's pharmaceutical intelligence unit, Humira (adalimumab) and two comparable antibodies that also target tumor necrosis factor-alpha, a cytokine involved in rheumatoid arthritis, will lead the list.

The trio will topple the cholesterol drug Lipitor (atorvastatin) and the blood thinner Plavix (clopidogrel) to become the world's top-selling medicines in 2012. Despite the smaller patient populations targeted by these biologics, the higher prices they demand can still translate into a sizeable market share, explains analyst Saurabh Aggarwal, principal of Novel Health Strategies, a life sciences consulting firm based in Bethesda, Maryland. "The pricing is a big factor that's driving the high sales in these products," he says.

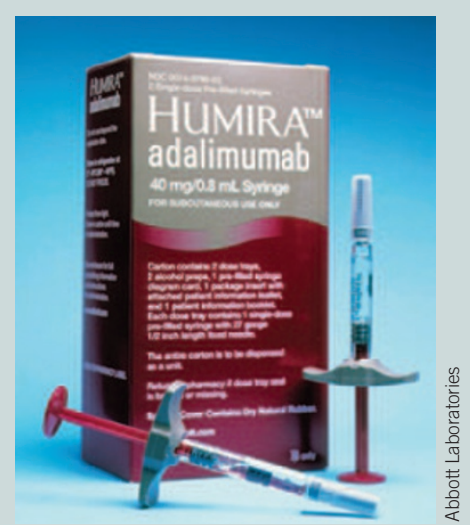

Primary indications

Drug type

\begin{tabular}{|c|c|c|c|c|}
\hline Drug & Projected 2012 sales & Company & Primary indications & Drug type \\
\hline Humira (adalimumab) & $\$ 9.3$ billion & Abbott Laboratories & Rheumatoid arthritis and psoriasis & Antibody \\
\hline Remicade (infliximab) & $\$ 9.1$ billion & Johnson \& Johnson & Rheumatoid arthritis and psoriasis & Antibody \\
\hline Enbrel (etanercept) & $\$ 8.1$ billion & Amgen & Rheumatoid arthritis and psoriasis & Antibody \\
\hline Advair (fluticasone/salmeterol) & $\$ 8.0$ billion & GlaxoSmithKline & $\begin{array}{l}\text { Asthma and chronic obstructive pulmonary } \\
\text { disease }\end{array}$ & Small molecule \\
\hline Rituxan (rituximab) & $\$ 7.1$ billion & Genentech/Roche & Blood cancers and rheumatoid arthritis & Antibody \\
\hline Crestor (rosuvastatin) & $\$ 7.0$ billion & AstraZeneca & Cardiovascular disease & Small molecule \\
\hline Avastin (bevacizumab) & $\$ 6.1$ billion & Genentech/Roche & Various cancers & Antibody \\
\hline Herceptin (trastuzumab) & $\$ 6.1$ billion & Genentech/Roche & Breast cancer & Antibody \\
\hline Lantus (insulin analog) & $\$ 5.9$ billion & Sanofi & Diabetes & Protein \\
\hline Abilify (aripiprazole) & $\$ 5.9$ billion & Bristol-Myers Squibb & Schizophrenia, bipolar disorder and depression & Small molecule \\
\hline
\end{tabular}

Source: Thomson Reuters Pharma

\section{Targeting hypoxia brings breath of fresh air to cancer therapy}

Solid tumors are often starved of oxygen, as new blood vessel formation typically can't keep pace with rapid cell division. Yet, rather than suffocating cancer tissue, this 'tumor hypoxia' usually renders cancer cells resistant to standard therapies, as oxygen is necessary to fuel the development of DNA strand breaks in radiation therapy and the dearth of blood vessels keeps circulating chemotherapy regimes away. Even with this elemental problem, however, some changes in hypoxic cells could actually result in increased drug sensitivity-a weakness that many drug developers hope to exploit for a next generation of tailored cancer treatments.

Leading the pack of so-called 'bioreductive prodrugs'-agents that become activated only in the oxygen-poor core of solid tumors-is Threshold Pharmaceuticals' TH-302. In a talk presented on 2 April at the American Association for Cancer Research's annual meeting in Chicago, Threshold announced the results of a phase 2 trial involving 214 people with advanced pancreatic cancer.
Compared with chemotherapy alone, the addition of TH-302 increased the average progression-free survival time from 3.6 to 5.6 months, the San Francisco-based drugmaker found.

"We are excited about the results," says Stewart Kroll, head of biostatistics and clinical operations at Threshold. "They have provided the proof of concept in a very difficult-to-treat indication."

These findings come on the heels of another phase 2 trial reported at last year's Connective Tissue Oncology Society meeting, also in Chicago, showing that TH-302 boosted the expected survival rates in people with soft-tissue sarcoma, a cancer of the body's connective or supportive tissues such as muscle, cartilage or fat. In February, Threshold announced that it was teaming up with Merck $\mathrm{KGaA}$, the German pharmaceutical company, to further develop and commercialize TH-302 for a range of cancers; and in March, the agent was granted orphan drug status in the US and Europe to treat soft-tissue sarcoma.
The road leading to drugs such as TH-302, however, has been long and rocky. "Designing prodrugs for hypoxia turns out to be a difficult challenge," says Bill Wilson, a cancer biologist at the University of Auckland in New Zealand and the cofounder of Proacta, a San Diegobased company developing hypoxia-activated agents. "The target cells are distant from the systemic circulation, so they present a difficult drug delivery problem."

Two years ago, for example, a promising drug candidate called tirapazamine failed in a phase 3 trial involving more than 800 people with head-and-neck cancer, in part because the agent, made by SRI International, a California-based nonprofit research institute, was activated by enzymes in oxygenrich regions and therefore used up before it reached the critical hypoxic cancer cells. Similarly, in April, Nevada-based Spectrum Pharmaceuticals announced that its drug apaziquone failed to meet primary endpoints in two phase 3 trials in patients with bladder cancer, but those results proved statistically 